\title{
SENTIDOS DO EXERCÍCIO DA LIDERANÇA POR MULHERES EXECUTIVAS BRASILEIRAS
}

\section{SENSES OF LEADERSHIP ENFORCEMENT BY BRAZILIAN EXECUTIVE WOMEN}

\section{Elaine Cristina Oliveira Rocha Nogueira}

Mestre em Administração pela Universidade Municipal de São Caetano do Sul - USCS

Professora de Ensino Superior da Universidade Nove de Julho - UNINOVE

E-mail: ecorocha1@ @otmail.com (Brasil)

\section{Edson Keyso de Miranda Kubo}

Doutor em Administração pela Escola de Administração de Empresas de São Paulo da Fundação Getúlio Vargas - EAESP/FGV

Professor do Programa de Pós-Graduação em Administração-Mestrado e Doutorado da Universidade Municipal de São Caetano do Sul - USCS

E-mail: edsonkubo@uscs.edu.br (Brasil) 


\title{
SENTIDOS DO EXERCÍCIO DA LIDERANÇA POR MULHERES EXECUTIVAS BRASILEIRAS
}

\section{RESUMO}

O objetivo desta pesquisa é analisar os sentidos de liderança por mulheres executivas brasileiras, visto que ampla maioria das pesquisas focaram os desafios da carreira (Lima, Lima, \& Tanure, 2009; Betiol \& Tonelli, 1991) com pouca ênfase para os desafios da liderança feminina nas organizações brasileiras. Utilizou-se de uma pesquisa exploratória, que se baseou em entrevistas em profundidade com treze mulheres que ocupavam cargos executivos em organizações empresariais dos segmentos da Educação, Indústria Manufatureira, Comércio, Serviços e Financeiro, nos estados de Pernambuco, Rio de Janeiro, São Paulo, Rio Grande do Sul e Minas Gerais. A pesquisa qualitativa, por meio da análise de conteúdo revelou que os sentidos da liderança para as mulheres executivas brasileiras se sintetizam essencialmente em aspectos relacionais do gênero feminino que são constituídos pela facilidade de comunicação, uso da intuição para a tomada de decisões, alto grau de relacionamento interpessoal com os membros da equipe, tomada de decisões compartilhadas com apoio e participação da equipe e utilização de equipes de trabalho mistas. Já os elementos dificultadores da liderança dessas executivas estão essencialmente relacionados aos aspectos objetivos da gestão, tais como falta de planejamento e despreparo da equipe, entre outros. Não obstante, questões relacionadas ao gênero, tais como estereótipos e resistência dos homens frente à liderança das mulheres também representam elementos que dificultam a liderança.

Palavras-chave: Mulher Executiva; Liderança; Estilo de Liderança; Sentidos de Liderança.

\section{SENSES OF LEADERSHIP ENFORCEMENT BY BRAZILIAN EXECUTIVE WOMEN}

\begin{abstract}
The aim of this research is to analyze the meaning of Leadership for Brazilian Executive Women, since a large majority of the research focused on the challenges of career (Lima, Lima, \& Tanure, 2009; Betiol \& Tonelli, 1991) with little emphasis on the challenges of female leadership in organizations. This article is based on exploratory research, which was based on in-depth interviews with 13 women who hold executive positions in organizations' business sectors such as Education, Manufacturing Industry, commerce and Financial Services in the states of Pernambuco, Rio de Janeiro, São Paulo, Rio Grande do Sul and Minas Gerais. The qualitative research through content analysis revealed that the meaning of leadership for Brazilian executive women are comprised essentially in interaction aspects of the female gender such as the ability towards communication, use of intuition for decision making, high degree of interaction with teams, shared decision making based on the participation of team members and mixed team working. When it comes to the elements that interfere in their leadership, those are primarily related to aspects of objective management, such as lack of planning and lack of team preparation, among others. However, issues related to gender, such as stereotypes and resistance manifested by men against the leadership of women also represent elements that block their leadership.
\end{abstract}


Elaine Cristina Oliveira Rocha Nogueira \& Edson Keyso de Miranda Kubo

Keywords: Executive Women; Leadership; Leadership Styles; Meanings of Leadership.

Revista de Gestão e Secretariado - GeSec, São Paulo, v. 4, n. 2, p 114-133, jul./dez. 2013. 


\section{INTRODUÇÃO}

Nas últimas décadas ocorreram significativas mudanças no padrão de inserção da mulher no mercado de trabalho e acompanhando esta tendência, as mulheres estão, gradualmente, ampliando sua presença no mundo corporativo (Melo, Considera, \& Di Sabatto, 2007). Desde a década de 1970, as mulheres vêm conquistando seu espaço no mercado de trabalho brasileiro.

Em 1976, o número de mulheres participantes da população economicamente ativa (PEA) no Brasil era de 11,4 milhões; porém, em 1990, esse número alcançou o índice de 22,9 milhões, crescendo ainda mais em 1998, quando chegou a 31,3 milhões e ainda de acordo com o IBGE (2008), de 1998 até 2008, o percentual de mulheres executivas cresceu de 25,9\% para 34,9\%.

As pesquisas sobre mulheres executivas são recentes no Brasil e na sua maioria abordam temáticas envolvendo: a) dificuldades de inserção da mulher no mercado de trabalho em cargos executivos (Lima, Lima \& Tanure, 2009; Betiol \&Tonelli, 1991); b) discriminação e preconceitos no ambiente profissional da alta hierarquia (Alcadipani, 2013) e c) conflitos inerentes à dupla jornada de trabalho no lar e no emprego (Carvalho, Tanure \& Andrade, 2010). Porém, foram pouco explorados os sentidos que as mulheres executivas brasileiras atribuem à liderança, visto que a maioria das pesquisas abordou os desafios da carreira (Cappelle, Mello, Brito, \& Brito, 2004; Lima, Lima, \& Tanure, 2009; Betiol \& Tonelli, 1991; Bruchini \& Lombardi, 1999; Carvalho, Carvalho \& Carvalho, 2001; Grzybovski, Boscarin \& Migott, 2002).

Considerando-se a inserção e a mudança de papéis da mulher no mercado de trabalho, coloca-se em discussão a diferenciação entre as características femininas e as masculinas de atuação no ambiente corporativo (Lima, Lima, \& Tanure, 2009). Assim, com o intuito de preencher a necessidade de se identificar e analisar os sentidos da liderança das mulheres executivas, este artigo tem como objetivo responder a seguinte pergunta: Que sentidos as mulheres executivas brasileiras atribuem à liderança?

Este artigo está estruturado em cinco partes: após esta introdução são apresentadas a revisão da literatura, a metodologia de pesquisa, a apresentação e discussão dos resultados e a conclusão.

Revista de Gestão e Secretariado - GeSec, São Paulo, v. 4, n. 2, p 114-133, jul./dez. 2013. 


\section{REVISÃO DA LITERATURA}

Nesta seção foram abordadas separadamente pesquisas sobre liderança e, em seguida, as pesquisas que trataram sobre a mulher executiva brasileira. Inicialmente, a seção sobre teorias da liderança discutiu os paradigmas e conceitos mais relevantes com base numa perspectiva diacrônica com a finalidade de acompanhar a evolução das teorias ao longo do tempo. Cumprida a primeira etapa, a revisão da literatura acadêmica abordou a mulher executiva brasileira, para mostrar os desafios enfrentados por essa profissional no nível executivo das organizações avaliando também aspectos da vida dessa mulher. O desenvolvimento deste tópico contribuiu para a identificação de lacunas teóricas sobre o tema pesquisado que possibilitou orientar a pesquisa de campo.

\subsection{LIDERANÇA E SEUS DESAFIOS CONCEITUAIS}

Conceituar liderança não é uma tarefa fácil, pois dependendo da área de conhecimento acadêmico as definições variam significativamente (Armond \& Nassif, 2009). O conceito de liderança é culturalmente influenciado e está sujeito a significados variados. Conforme Bass (1990, p. 11) "existem quase tantas definições de liderança como existem pessoas que têm tentado definir este conceito", motivo que leva até o momento, à evidência de muitas definições sobre o assunto. Davel e Machado (2001), por exemplo, definem a liderança como sendo a capacidade de influenciar e direcionar os liderados. Além disso, os autores acrescentam que a liderança é um fenômeno social e complexo presente nas organizações, que sofre influência dos traços de personalidade, estilos de comportamento e fatores contingenciais dos líderes e liderados. Para esses autores, o líder é um profissional responsável pela formação de equipe e pelo controle e monitoramento dessa equipe, de modo que esse venha a exercer um papel comprometido e dentro das necessidades da empresa.

Ao realizar um levantamento sobre conceitos de liderança, observou-se que poderia haver dois tipos de liderança: os clássicos e os contemporâneos. Os clássicos estariam focados em hierarquia e resultados e os contemporâneos estariam focados no aspecto relacional (Bergamini, 1994; Hersey \& Blanchard,1986; Boluda \& Valenzuela, 2011; Weathersby, 1999; Cardoso \& Amorin, 2010; Souza, 2012).

Observa-se que a liderança, em sua perspectiva contemporânea, inclui elementos tradicionais (tais como as metas a serem alcançadas) e elementos atuais, tais como estratégias diferentes do líder se relacionar com seus liderados para que as metas sejam alcançadas. A meta ou resultado é um elemento basilar para qualquer teoria da liderança, porém o modo como o líder

Revista de Gestão e Secretariado - GeSec, São Paulo, v. 4, n. 2, p 114-133, jul./dez. 2013. 
interage com seus liderados para que a meta seja alcançada, é tratada de modo diferente em cada teoria. Neste artigo, optou-se por adotar a definição contemporânea de liderança que contempla o aspecto relacional, envolvendo o líder e a equipe de trabalho. O aspecto relacional é a base das teorias Transformacional e Transacional de Liderança (Tannenbaum \& Schmidt, 1986; Bass, 1990; Robbins, 2002; Riche, 2009; Souza, 2012).

Dentre as teorias de liderança, as abordagens transformacional e transacional são as mais influentes no campo de estudo da administração (Bass, 1997; Souza, 2007; Avolio \& Bass, 2004; Rafferty \& Griffin, 2004), porém há importantes distinções entre ambas as abordagens. A abordagem "transformacional" parte do pressuposto de que o líder tem como "missão" mudar as atitudes e os valores dos seus liderados, de modo que eles assimilem as necessidades e os objetivos organizacionais para alcançar resultados (Avolio \& Bass, 2004; Bass, 1990).

Os líderes transformacionais estimulam em seus liderados a confiança, buscam desenvolver a liderança própria e atuam como agentes morais no sentido de despertar o senso crítico. Essas mudanças de atitudes que são estimuladas pelo líder têm como objetivo último fazer com que os liderados transcendam as necessidades mais imediatas do grupo de trabalho. A liderança transformacional define um líder como aquele que, com sua visão pessoal e sua energia, inspira os seus seguidores e causa impacto significativo na organização, ou seja, a preocupação da liderança transformacional concentra-se na mudança de valores e atitudes dos liderados (Bass, 1997).

Assim, os líderes transformacionais usam processos de influência de ordem superior quando comparados com os líderes transacionais, além disso, os líderes transformacionais não se limitam a reagir aos problemas tal como os recebem, questionam-se de modo a contribuir para a construção de um objetivo coletivo, enquanto os líderes transacionais se limitam a resolver os problemas para alcançar os objetivos traçados. Nota-se, portanto, que a abordagem transacional é altamente instrumental, isto é, o interesse do líder está unicamente direcionado para os resultados concretos alcançados pela equipe liderada (Bass, 1997).

Como este artigo foca a mulher executiva brasileira, faz-se necessário discutir a questão do "gênero" e da liderança, pois o fato de ser mulher parece interferir em sua inserção no mercado de trabalho como executiva e também no exercício prático da liderança.

Revista de Gestão e Secretariado - GeSec, São Paulo, v. 4, n. 2, p 114-133, jul./dez. 2013. 


\subsection{A MULHER EXECUTIVA BRASILEIRA}

Observa-se cada vez mais o crescimento da presença da mulher em cargos executivos. Por esse motivo, um número cada vez maior de pesquisas acadêmicas tem se interessado em procurar entender e explicar a tendência de crescimento da presença de mulheres em cargos de comando nas organizações (Tanure, Carvalho, \& Andrade, 2007; Betiol \& Tonelli, 1991). Alguns autores, como Lima, Lima e Tanure (2009), destacaram, em suas pesquisas, que o crescimento da presença da mulher em cargos executivos só não é maior devido aos vários desafios enfrentados por essa profissional em nível executivo das organizações, porque existem barreiras socioeconômicas que impedem o avanço pleno das mulheres em cargos de comando, sobretudo se comparada ao homem.

Outro desafio citado pelos autores se refere à discriminação da mulher executiva quando há avaliação de líderes, visto que os comportamentos exibidos por um líder masculino são avaliados de forma mais favorável do que comportamentos idênticos exibidos por uma líder feminina. Por exemplo, um homem que tem uma atitude intempestiva é, com frequência, avaliado como preocupado e comprometido com a organização, ao contrário da mulher. Essa característica marcante, entre outras, identificada pela pesquisa, está vinculada a distinção entre "razão" e "emoção" envolvendo comportamentos entre os gêneros. Os resultados da pesquisa desses autores mostram que a mulher apresenta relativamente maior uso da emoção (atributo: sentimento) que razão (atributo: pensamento) em cargos gerenciais, quando comparada ao homem.

Levando-se em consideração as dificuldades de ascensão na carreira executiva, convém explorar as diferenças de gênero e sua influência na atuação em cargos de liderança. Dentro desse enfoque, destaca-se a pesquisa de Helfat, Harris, e Wolfson (2006), que deram ênfase aos fatores que levam as empresas, em muitas situações, a preferirem as mulheres em cargos de alta gerência. Esse estudo destacou, em primeiro plano, que a preferência das empresas por contratar mulheres para cargos elevados, reside na diferença de comportamento naquilo que elas já gerenciavam no decorrer das suas vidas. Ou seja, as mulheres gerenciavam suas vidas de forma dinâmica, conciliando o profissional e o pessoal. Essa característica foi também notada por outra pesquisa de Neto, Tanure e Lima, (2010), que ao comparar 965 executivos homens e mulheres de vários setores, avaliaram o comportamento dessas pessoas no mundo corporativo e na vida pessoal e concluíram que as mulheres têm de administrar além do cargo, os preconceitos arraigados; pressão do relógio biológico; sobrecarga com os cuidados em relação aos filhos versus jornada de trabalho muito extensa. Outra característica relevante dessa pesquisa refere-se ao fato de que as mulheres executivas se adaptam facilmente ao ambiente corporativo e à cultura organizacional.

Revista de Gestão e Secretariado - GeSec, São Paulo, v. 4, n. 2, p 114-133, jul./dez. 2013. 
Gary, Carter e Franit (2010) pesquisaram a relação entre mulheres diretoras e o desempenho financeiro das empresas e concluíram que essas executivas não são substitutas dos homens nesses cargos, mas que elas podem ter atributos únicos, tais como maior facilidade de comunicação, bom relacionamento interpessoal e empatia que implicam melhoria da performance do conselho de administração e da organização. Isso significa que essas executivas oferecem um adicional e/ou fonte singularmente qualificada de talentos e as organizações podem ser capazes de aumentar o valor para seus stakeholders.

De acordo com Mourão e Galinkin (2008), nota-se que, quando se trata de postos executivos na administração pública, as mulheres têm obtido mais oportunidades de ocupar esses cargos, visto que o ingresso ocorre mediante critérios de qualificação profissional e seleção por meio de concursos públicos, que constituem métodos impessoais de contratação. Evidentemente, que no Brasil, deve-se considerar que as áreas de atividades públicas mais favoráveis às mulheres continuam sendo a de serviços comunitários e sociais, porque já estão mais representadas e têm maiores oportunidades de ocuparem cargos gerenciais (Mourão \& Galinkin, 2008). Com base nesta realidade, os autores realizaram a pesquisa tendo como foco a Polícia Federal, uma instituição pública altamente hierarquizada e que tem demanda de trabalho qualificado. O objetivo desta pesquisa foi aprender a maneira como as equipes, que são lideradas por mulheres, constroem representações sociais sobre sua posição de comando. Concluíram que as equipes lideradas por mulheres apresentavam algumas características distintas, tais como: maior imersão na atividade profissional, maior comprometimento com as tarefas e resultados e aceitação da posição hierárquica.

Betiol e Tonelli (1991), numa pesquisa sobre a mulher executiva, destacam a importância dos papéis sociais, envolvendo diferenças de gênero, ao ressaltar que as mulheres correm menos riscos no que tange aos negócios, porque são naturalmente protegidas pela sociedade. Entretanto, o que pode parecer uma vantagem, muitas vezes transparece como fator gerador de discriminação em ambientes organizacionais. As autoras também assinalam que o desempenho da mulher executiva, seja ele satisfatório ou não, depende do clima organizacional, visto que empresas tradicionalmente conduzidas por homens possuem certo receio em admitir que uma executiva inove os métodos de gestão. Dentro desta mesma linha de pesquisa, pode-se apontar o estudo de Ouimet (2003), ao assinalar enfaticamente que dentro das empresas existe um quadro onde é necessária a aceitação de manipulação de jogos dentro da liderança executiva para o contexto feminino, pois como afirmado 
pelo autor, as mulheres estão completamente imersas neste constante jogo cheio de preconceitos e boicotes masculinos.

Para Lodi (1999), as mulheres executivas apresentam características como a humildade, maior estabilidade emocional, objetividade, paciência, autorrenúncia e disposição para operar em ambiente de contrariedade, disposição para negociar fazendo menos concessões e sua inteligência geral são enriquecidas pela intuição, assim administram de forma diferente daquela dos homens. $\mathrm{O}$ autor, ainda, destaca que as mulheres dirigentes são humildes para aceitar situações de desmotivação por período prolongado, apresentam também maior estabilidade emocional apoiada numa maturidade psicológica, têm maior disposição para uma pronta superação das frustrações e são objetivas e persistentes (uma vez definida a área e a metodologia de trabalho, segue-se uma linha mais disciplinada). Além disso, as mulheres executivas demonstram paciência, disposição para começar de baixo, aprender com a modéstia, suportar condições impróprias, bem como maturidade para tarefas de housekeeping, ou seja, administrar serviços sob condições específicas de desempenho e em ambientes estáveis.

As mulheres buscam apoio de sua equipe para tomar decisões, são mais receptivas, cuidadosas, o que implica um tempo maior para decidir sobre alguma coisa, porém suas respostas, na maioria das vezes, são assertivas e garantem a eficiência que se traduz em bons resultados para a empresa (Lodi, 1999).

$\mathrm{O}$ autor conclui que quando a mulher conquista um cargo que seria exclusivo para homens, essas qualidades próprias do gênero feminino são interpretadas como competência profissional. E para conquistar ainda mais espaço no mercado de trabalho as mulheres executivas também são capazes de assimilar as características de liderança propriamente masculinas.

Considerando a exposição do conjunto de pesquisas sobre as diferenças de estilos de liderança envolvendo as diferenças de gênero, pode-se observar que a mulher demonstra ter uma maneira própria e peculiar de conduzir a gestão dos negócios corporativos. Além dessas diferenças de estilos de liderança, há que se destacar que todas as pesquisas relacionadas às mudanças do mercado de trabalho no Brasil são categóricas ao apontar o avanço das mulheres em atividades profissionais que até há pouco tempo eram exclusivamente exercidas por homens, a exemplo de profissões liberais relacionadas aos cargos executivos de administração corporativa.

Assim, esta seção apresentou os resultados das pesquisas envolvendo as mulheres nas organizações em cargos de comando, ao abordar os desafios inerentes à sua atuação no mundo corporativo. Foi possível observar que: 1) as mulheres executivas parecem ter um estilo de liderança diferente dos homens; 2) as mulheres sofrem preconceitos e são comparadas aos 
homens em suas atividades como executivas; e 3) a inserção da mulher no mercado não é proporcional à sua participação enquanto líder nas organizações.

\subsection{SENTIDOS DA LIDERANÇA}

A liderança, conforme visto no decorrer da revisão da literatura, pode ser vista como uma prática social, pois envolve a relação entre o líder (no caso a mulher executiva brasileira) e os seus liderados (equipe de colaboradores). Por essa razão, ao buscar compreender os sentidos que as mulheres brasileiras atribuem à liderança, este artigo se utiliza da visão de Berger e Luckmann (1985) e de Weick (1995), que defendem a ideia de que a realidade é socialmente construída e que por esse motivo os sentidos são conferidos de acordo com o tipo de relação social que ocorre entre os atores, com o intuito de ordenar os significados e a interpretação de uma dada realidade.

Assim, não se pode falar em sentidos de liderança sem compreender as percepções que a mulher executiva brasileira possui a respeito da relação com sua equipe e com o ambiente organizacional no qual está inserida, que é fruto de uma construção social. Discorrer sobre os sentidos de liderança para essas mulheres é abordar, portanto, o modo como interpretam o ato de liderar diante de elementos que facilitam ou dificultam o seu exercício.

\section{METODOLOGIA}

A pesquisa exploratória é adequada para alcançar o objeto de pesquisa deste artigo, pois os sentidos de liderança por mulheres executivas brasileiras não estão em evidência na literatura acadêmica. De modo geral, podem-se destacar as seguintes vantagens do uso da pesquisa exploratória: a) contribui para a análise de temas ou assuntos pouco estudados pela literatura acadêmica; b) proporciona visão geral acerca de determinado fenômeno, em razão de sua complexidade; e c) permite a formulação de hipóteses mais precisas, tornando-as operacionalizáveis bem como possibilita aprimorar a investigação sobre determinado fenômeno (Creswell, 2007; Gil, 2002).

Esta pesquisa utilizou-se de um survey exploratório que está estruturado em entrevistas individuais e em profundidade, com um roteiro predefinido de questões. Vale lembrar que a

Revista de Gestão e Secretariado - GeSec, São Paulo, v. 4, n. 2, p 114-133, jul./dez. 2013. 
entrevista é uma técnica utilizada em pesquisas qualitativas, porque permite o levantamento de uma variedade de informações sobre o tema estudado.

O principal objetivo desta técnica é a obtenção de informações sobre determinado assunto ou problemática, em que o entrevistado detenha conhecimento ou vivência do assunto de modo que possa contribuir com elementos essenciais para essa pesquisa, de cunho qualitativo (Malhotra, 2005; Lakatos \& Marconi, 2001; Gil, 1994).

$\mathrm{O}$ universo da pesquisa abrange mulheres executivas brasileiras (presidentes, vicepresidentes, diretoras e gerência de terceiro nível, logo abaixo dos diretores ou vice-presidentes), provenientes dos estados de São Paulo, Rio de Janeiro, Pernambuco, Minas Gerais, Rio Grande do Sul, de empresas de médio e grande porte (nacionais e multinacionais), de segmentos variados da atividade econômica, incluindo os ramos de serviço, automotivo, químico, metalúrgico, educação e logística.

No que se refere ao número de entrevistas, a amostra agrupou treze entrevistas com mulheres executivas que ocupavam cargos de liderança entre o primeiro e terceiro escalões da hierarquia organizacional. A tabela 4 apresenta as características gerais do perfil sócio-demográfico da amostra.

Tabela 4 - Perfil sócio-demográfico da amostra

\section{Faixa Etária}

18 a 25 anos

26 a 35 anos

36 a 50 anos

51 a 60 anos

Acima de 61 anos

\section{Estado Civil}

Casada 9

Solteira... 1

Divorciada 3

Viúva

Cargo

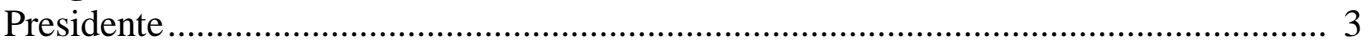

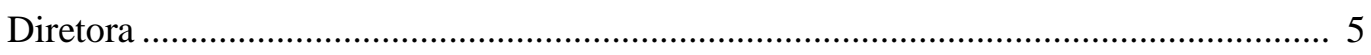

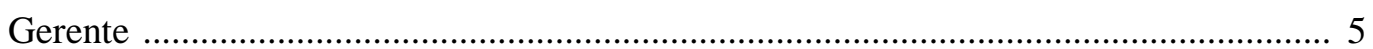


Somente Ensino Fundamental

Somente Ensino Médio

Superior completo 1

Pós-graduação

\section{Segmento de atuação da empresa}

Indústria 5

Comércio 3

Serviços. 3

Financeiro 2

\section{Tempo em cargo executivo}

1 a 5 anos 1

6 a 10 anos 3

11 a 15 anos 4

Acima de 16 anos 5

\section{Estados de origem das entrevistadas}

São Paulo 5

Rio de Janeiro 3

Pernambuco. 2

Minas Gerais 2

Rio Grande do Sul. 1

Fonte: Elaborado pelos autores.

A análise dos dados foi efetuada por meio da transcrição das entrevistas que foram codificadas em torno da categoria sentidos da liderança. Os autores Godoi, Bandeira-de-Mello e Silva (2006) definem o código como uma abstração que permite ao pesquisador efetuar a análise dos dados específicos, de modo que esses dados se transformem em conceitos e categorias. O procedimento para a validação da categoria principal deste artigo ocorreu com a verificação do nível de ocorrência dos códigos. As entrevistas foram analisadas após a transcrição, utilizando-se a técnica de análise de conteúdo (Bardin, 2011).

O critério de seleção das entrevistadas foi baseado por acessibilidade (indicações e contatos pessoais). Ao todo foram coletadas treze entrevistas no período de setembro a outubro de 2012 e a duração média das entrevistas foi de 1h30min, tempo suficiente para dar conta de todas as questões contidas no roteiro. As entrevistas foram gravadas e transcritas, preservando-se todas as informações sigilosas tais como nome entre outros dados pessoais. O roteiro com dez questões principais, elaborado à luz da revisão da literatura, abordou o cotidiano das executivas e dos elementos facilitadores e dificultadores no exercício da liderança, tais como: Você acha que faz 
realmente o que deveria estar fazendo como líder? O que dificulta a sua liderança? O que facilita a sua liderança? O que é liderança para você?

As entrevistas configuraram a abordagem utilizada para a coleta de dados que possibilitou classificar de metodologia qualitativa, a pesquisa na qual se apoiou este artigo, para investigar os sentidos conferidos às práticas da liderança por essas executivas brasileiras.

\section{APRESENTAÇÃO E DISCUSSÃO DOS RESULTADOS}

Enquanto ocupantes de cargos executivos, as entrevistadas foram identificadas de modo sigiloso, por meio de siglas, tais como entrevistada 1 (E1), E2, E3, dentre outras e apenas as citações mais representativas foram escolhidas na hora de apresentar os dados. Indagou-se inicialmente sobre o significado que as executivas atribuem à liderança e observou-se que houve similaridade nas respostas, que podem ser representadas por E3, E4 e E5:

E3: Eu acredito que liderança é você conseguir alcançar um objetivo através de outras pessoas. Porque é muito fácil você alcançar um objetivo através da sua própria conduta pessoal, de você correr atrás e fazer. Porém, liderar é conseguir que aquela equipe de pessoas alcance esse objetivo em comum, e isso para mim é liderança.

E4: Tenho um conceito de liderança que vai além do aspecto de dirigir ou gerenciar pessoas. Para mim liderança é você ter responsabilidade e influenciar as outras pessoas sobre algo que você conhece bem e que você sabe fazer muito bem.

E5: Para mim liderança é a capacidade de levar um grupo ou um indivíduo a caminhos e objetivos traçados por você e ter a capacidade de saber trabalhar o potencial de cada colaborador, pois cada um tem um perfil de trabalho, mas o objetivo é um só. Há uma diferença entre liderar e ser gestor, pois o líder que se preza deve seguir uma liderança baseada no exemplo. Eu lidero, mas também trabalho, ou seja, tenho que dar conta dos aspectos burocráticos que envolvem o trabalho de gestão. Quero que minhas lideradas produzam e trabalhem, e eu devo fazer a mesma coisa em campo para dar exemplo. Agora gestor não, ele apenas acompanha os liderados cobrando os resultados.

Conforme ilustrados por E3, E4 e E5, a liderança é percebida como um fenômeno relacional, porque envolve o líder e os liderados, com ênfase na equipe de trabalho. Há claras referências sobre corresponsabilidade entre o líder e os liderados que envolvem a ação do líder, no sentido de direcionar a equipe de trabalho na realização de tarefas para atingir determinados resultados. Isso fica evidente, pois a mulher executiva sabe o que quer e como deve alcançar seus objetivos (E4) e precisa da equipe para esse fim (E3). Parece haver entre as entrevistadas, uma consciência de que os bons resultados alcançados dependem de uma orientação clara e objetiva para a equipe, o que pode 
ser observado na citação representativa de E5.

As entrevistadas também afirmaram que ser gestor é lidar com a parte burocrática, com o andamento prático do processo e que ser líder é lidar com pessoas, como já foi referenciado. A percepção de liderança das entrevistadas se aproxima da teoria transformacional de liderança ao se engajarem em dar uma causa e não uma meta, ao enfatizarem o envolvimento e comprometimento com a tarefa (Avolio \& Bass, 1995; Souza, 2007). Isso pode ser observado, por exemplo, em E4:

E4 - É uma tarefa difícil; pois tenho que inspirá-los. Eu tenho informações, tenho mais experiência pra entender o todo, o mercado, a situação da empresa. Portanto, pra mim é um processo de inspiração, tem que traduzir pra eles a situação mais geral e o papel da organização, como empresa, para concretizar resultados. Neste aspecto, acho que tem um fator muito importante que é o que eu chamo de confiança: a confiança como a gente fala, como a gente trata, e assim consigo conquistar os colaboradores que são meus subordinados. Creio que este fator deve ser observado por qualquer líder, e pra mim, tem sido fundamental conquistar a confiança do meu time, para que vejam o que temos que realizar juntos.

Conforme relatado em E4, observa-se a preocupação não apenas com o alcance das metas, mas de conferir um significado ao trabalho diário dos colaboradores de modo a inspirá-los. A liderança não se prende apenas a aspectos formais de comando ou metas, mas também se preocupa em dar um sentido às atividades dos funcionários, priorizando uma relação de confiança que pode reforçar a coesão do "time" de trabalho.

As executivas recompensam e estimulam suas respectivas equipes de trabalho com benefícios materiais na forma de aumento de salário, bonificação e promoção. Porém, destacam a necessidade do relacionamento mais próximo com os integrantes da equipe, no sentido de considerar os aspectos humanos de qualidade de vida no trabalho. Os elementos mencionados nos depoimentos que corroboram essa afirmação são os seguintes: 1) a líder faz parcerias com a equipe. Isso significa que o líder atua junto aos liderados tentando perceber dificuldades na realização do trabalho, buscando superar obstáculos; 2) a líder recompensa e estimula a equipe com reconhecimento pelo trabalho eficiente atribuindo aos integrantes da equipe o mérito do trabalho concretizado com sucesso; e 3) a líder provê bem-estar para sua equipe, tais como permitir que o trabalhador tenha flexibilidade de horário, em alguns casos permitir que ele possa trabalhar em casa (home office).

Observa-se que em todos os depoimentos citados, as entrevistadas tomam decisões conjuntas com suas respectivas equipes. Além de afirmarem isso, procuram dar explicações da importância de se tomar decisões compartilhadas. 
Os argumentos que são apresentados nos depoimentos podem ser considerados como elementos estimuladores para a equipe, ou seja, quando o líder toma decisões compartilhadas ele também está preocupado em mostrar para os integrantes da equipe sua devida importância na empresa e no processo de trabalho como um todo. Decisões compartilhadas servem como estratégia de valorização da equipe e também como modo eficaz de alcançar resultados, mas isso depende do grau de maturidade da equipe com que se trabalha (Hersey \& Blanchard, 1986).

As entrevistas também tiveram o objetivo de mapear características próprias do gênero feminino que podem vir a influenciar o exercício da liderança. A ideia de abordar esse aspecto, nesta pesquisa, está relacionada com alguns estudos sobre mulheres em cargos executivos que identificaram uma série de atributos próprios do gênero feminino no ambiente corporativo, envolvendo cargos de liderança, comparando-os com atributos do gênero masculino. Autores como Lima, Lima e Tanure (2009), em uma pesquisa sobre crescimento da presença da mulher em cargos executivos, notaram que as mulheres utilizam muito mais a intuição na forma de insights para tomada de decisão e no relacionamento com os demais, conforme mostra E9 e E10, dentre outras mulheres executivas:

E9 - Eu acho que nós mulheres temos o sexto sentido, que os homens não têm. E acho que isso ajuda bastante. Sou muito franca, eu aviso. Eu mesmo falo: olha isso está ok, isso não está ok, vamos fazer novamente. Vamos fazer de uma forma diferente e vamos trabalhar pra tentar alcançar.

E10 - Tem que usar a percepção não é. Sem intuição como é que você faz as coisas? Sou muito transparente. É muito fácil descobrir quando eu estou satisfeita ou insatisfeita com alguma coisa. Na verdade é assim a minha fisionomia, o meu jeito de ser é muito claro nesse aspecto fica muito fácil deles notarem.

Observou-se também nas entrevistas, que para as mulheres executivas, o ideal seria liderar uma equipe mista, composta tanto por homens quanto por mulheres, pois cada um dos gêneros têm seus atributos. Observou-se das entrevistas no ambiente de trabalho, que as mulheres valorizam a proximidade, o diálogo e informações detalhadas para executar o trabalho e os homens valorizam ações práticas, não se prendem a detalhes e concluem o trabalho com mais rapidez.

É importante enfatizar que as diferenças de gêneros se configuram como conflitos de sociabilidade interna ao ambiente corporativo que expressam os papéis sociais característicos de cada gênero (Ouimet, 2003). Exemplos desses conflitos de sociabilidade são bastante evidentes e aparecem nos conteúdos das entrevistas: 1) contratação de um homem na equipe para tentar diluir as rivalidades femininas dentro do próprio grupo; 2) as mulheres com quem algumas das entrevistadas já trabalharam tinham dificuldade de lidar com o jogo corporativo; 3) o homem é 
mais disciplinado quando se trata do cumprimento de prazos e horários; 4) as mulheres são extremamente difíceis de lidar em épocas de Tensão Pré-Menstrual (TPM); e 5) tem homens que não gostam de ser liderados por mulheres.

Portanto, observou-se por meio do conteúdo das entrevistas, que a liderança dessas executivas é marcada pela comunicação e relacionamento interpessoal com os membros de equipe, pois buscam por decisões compartilhadas, usam da intuição e preferências por equipes mistas de trabalho, visto que as próprias mulheres reconhecem que não é fácil trabalhar com mulheres.

A discussão dos resultados finais aponta para a importância do aspecto relacional envolvendo a líder e os liderados. Esse aspecto relacional é a base das teorias contemporâneas de liderança (especialmente o transformacional).

A análise do conteúdo também revelou elementos dificultadores da liderança das mulheres executivas. Esses elementos se referem essencialmente ao comportamento e atitudes dos membros da equipe. Em relação aos elementos dificultadores, observa-se a partir das entrevistas que se referem aos aspectos objetivos da gestão e independem do gênero, tais como deficiências em planejamento e cumprimentos de prazos, resistência à mudança por parte da equipe, despreparo por parte da equipe etc. Não obstante, há também as queixas de homens que não apreciam ser liderados por mulheres, devido também aos estereótipos e, além disso, as executivas tendem a ver outras mulheres como rivais e preferem trabalhar com homens.

Quando se observam os elementos facilitadores, percebe-se uma sutil diferença, pois além da menção à equipe, são apresentados atributos positivos associados, exclusivamente com o modo pessoal de as executivas exercerem a liderança, tais como uso da intuição, facilidade de comunicação, alto grau de relacionamento interpessoal com a equipe, capacidade de tomar decisões compartilhadas e recompensas aos liderados.

\section{CONSIDERAÇÕES FINAIS}

Embora o objetivo desta pesquisa não tenha sido o de caracterizar os estilos de liderança da mulher executiva brasileira é importante enfatizar que os elementos facilitadores e dificultadores para o exercício da liderança feminina trazem implícita uma correlação entre estilos de liderança e modos de se relacionar com a equipe. 
Da perspectiva das executivas, a interação com seus liderados está alicerçada numa relação de proximidade. Essa relação de proximidade tem a ver com a interação dinâmica entre líder e liderado e se enquadra nos estilos de liderança contemporâneos, que consideram líderes e liderados como uma unidade simbiótica. Na perspectiva das executivas, o trabalho de gestão é uma atividade preponderantemente burocrática que envolve processos administrativos, já o exercício da liderança é um trabalho de caráter relacional, envolvendo pessoas e suas respectivas atitudes, sentimentos, percepções e motivações.

Portanto, independente da faixa etária de cada uma das executivas, do segmento empresarial que cada uma atua, bem como do número de subordinados e da estrutura hierárquica na qual estão inseridas, há características comuns que ajudam a compreender os sentidos de liderança.

Respondendo à pergunta de pesquisa, deste artigo, quanto aos sentidos que as mulheres executivas brasileiras atribuem à liderança, observou-se que esses sentidos se sintetizam essencialmente em aspectos relacionais do gênero feminino, que são constituídos pela facilidade de comunicação, uso da intuição para a tomada de decisões, alto grau de relacionamento interpessoal com os membros da equipe, tomada de decisões compartilhadas com apoio e participação da equipe e utilização de equipes de trabalho mistas.

Ao analisar a categoria que envolve os elementos facilitadores e dificultadores para o exercício da liderança, observa-se que o comprometimento e maturidade da equipe determinam em grande parte os elementos facilitadores e dificultadores. Neste ponto, é possível associar os achados desta pesquisa de campo com os estudos de Hersey e Blanchard (1986). Os autores citados consideram importante avaliar as características do grupo de liderados para se entender o grau de maturidade da equipe e as influências que esse grau de maturidade exerce sobre o exercício da liderança. Maturidade da equipe é um "conceito-chave" para os autores, porque envolve a capacidade e disposição das pessoas que integram determinada equipe de trabalho em assumir responsabilidades na realização de tarefas.

Com base no conjunto de depoimentos, pode-se afirmar que as executivas da amostra adotam um estilo de liderança transformacional pois, em seus respectivos trabalhos, elas demonstram alto grau de envolvimento com as suas equipes. Essa proximidade com a equipe pode ser entendida como um processo dinâmico que se caracteriza pelos seguintes aspectos: procuram inspirar os membros das equipes de trabalho, transformam metas em causas, descobrem e capacitam novos líderes, empenham-se em tomar decisões compartilhadas e estimulam e recompensam as equipes de trabalho (envolvendo mérito e reconhecimento).

Revista de Gestão e Secretariado - GeSec, São Paulo, v. 4, n. 2, p 114-133, jul./dez. 2013. 
Por último, é necessário retomar a discussão sobre a inserção da mulher no mercado de trabalho no Brasil, considerando a tendência contemporânea do crescimento da presença de mulheres em cargos executivos. Sobre esse assunto, os depoimentos coletados e analisados sob a perspectiva da inserção profissional revelam que as barreiras sociais que limitaram a inserção da mulher no mercado de trabalho ainda existem. É possível identificar posturas e percepções estereotipadas que interferem na trajetória profissional e do universo relacional no cotidiano de trabalho, de cada uma das entrevistadas.

\section{REFERÊNCIAS}

Alcadipani, R. (2013). Macho, adulto e branco. GV Executivo (Vol.12, n. 1, p.74).

Armond, A. C., \& Nassif, V. M. J. (2009). A liderança como elemento do comportamento empreendedor: um estudo exploratório. RAM - Revista de Administração Mackenzie (Vol. 10, No. 5, pp. 77-106). São Paulo: Mackenzie.

Avolio, B. J., \& Bass, B. M. (2004). Multifactor leadership questionnaire: Third edition manual and sampler set. Redwood City, CA: Mind Garden.

(1995). Individual consideration viewed at multiple levels of analysis: A multi-level framework for examining the diffusion of transformational leadership, The Leadership Quarterly (Vol. 6, n. 2, pp. 199-218).

Bass, B. M. (1997) "Does the Transactional - Transformational Leadership Paradigm Transcend Organizational and National Boundaries?". American Psychologist, (Vol. 52, n. 2, pp. 130-139).

. (1990) "From transactional to transformational leadership: learning to share the vision", Organizational Dynamics (Vol. 18, n. 3, pp. 19-31)

Bardin, L. (2011). Análise de conteúdo. Lisboa: Edições 70.

Bergamini, C. W. (1994). Liderança: a administração do sentido. Revista de Administração de Empresas (Vol;. 34, n. 3, pp. 102-114, mai.jun.), São Paulo.

Berger, P. \& Luckmann, T. (1985). A construção social da realidade: tratado sobre a sociologia do conhecimento. Petrópolis: Vozes. 
Betiol, M. I. S., \& Tonelli, M. J. (1991). A mulher executiva e suas relações de Trabalho. Revista de Administração de Empresas. (Vol.31, n. 4, pp. 17-33 out./dez). São Paulo.

Boluda, I. K., \& Valenzuela, M. E. A.(2011). El estilo de liderazgo y la orientación al mercado: Su repercusión en la satisfacción en el trabajo del docente universitário. GCG. Georgetown University - Universia (Vol. 5, n. 3, pp. 64-79, sep/dec).

Bruchini, C. \& Lombardi, M. R. (1999). A bipolaridade do trabalho feminino no Brasil: o emprego doméstico e as "novas" ocupações. Mulher e Ocupação (Vol. 110, n.1, pp. 67-104).

Cappelle, M. C. A., Mello, M. C. O. L., Brito, M. J. M., \& Brito, M. J. (2004) Uma análise da dinâmica do poder e das relações de gênero no espaço organizacional. RAE- eletrônica (Vol. 3, n. 2, Art. 22, jul./dez.).

Cardoso, P. A., \& Amorin, M. C. C. (2010). Liderança e âncoras de carreira: uma experiência de identificação dos perfis dos líderes. Revista do Programa de Estudos Pós-graduados em Administração-FEA. (Vol. 25, Issue 1, pp. 61-78).

Carvalho, M. P. F. S., Carvalho, J. L. F. S., \& Carvalho, F. A. (2001) O ponto de vista feminino na reflexão ética: histórico e implicações para a teoria de organizações. Enanpad, 25, Anais de Congresso. [CD-ROM.]

Carvalho Neto, A. M., Tamure, B., \& Andrade, J. (2010). Executivas: Carreira, maternidade, amores e preconceitos. RAE-eletrônica. (Vol.. 9, n. 1, Art. 3, jan./jun.)

Creswell, J. W. (2007). Projeto de pesquisa: métodos qualitativo, quantitativo e misto. (2a ed.). Porto Alegre: Artmed.

Davel, E., Machado, H. V. (2001) A dinâmica entre liderança e identificação: sobre a influência consentida nas organizações contemporâneas. RAC (Vol.. 5, n. 3, set./dez., pp. 7-126).

Gary, S., Carter, D., \& Franit, D. (2010) What doWe Know About Women on Boards? Journal of Applied Finance (Vol. 20, n.2, set., pp. 27-39).

GIL, A. C. (2002). Como elaborar projetos de pesquisa. (4a ed.). São Paulo: Atlas. . (1994). Metodologia do ensino superior. São Paulo: Atlas.

Godoi, C. K., Bandeira-de-Melo, R., Silva, A. B. (orgs.) (2006). Pesquisa qualitativa em estudos organizacionais: paradigmas, estratégias e métodos. São Paulo: Saraiva.

Grzybovski, D., Boscarin, R., \& Migott, A. M. B. (2002). Estilo feminino de gestão em empresas (c) EY familiares gaúchas. RAC (Vol.. 6, n. 2, maio/ago. pp. 185-207).

Revista de Gestão e Secretariado - GeSec, São Paulo, v. 4, n. 2, p 114-133, jul./dez. 2013. 
Helfat, C. E., Harris, D., \& Wolfson, P. (2006). The pipeline to the top: women and men in the top executive ranks of u.s. corporations. Academy of Management Perspectives. November.

Hersey, P., \& Blanchard, K. H. (1986). Psicologia para administradores: a teoria e as técnicas da liderança situacional. São Paulo: EPU.

IBGE-Instituto Brasileiro de Geografia e Estatística. (2008). Perfil das mulheres responsáveis pelos domicílios no Brasil 2000. Departamento de População e Indicadores Sociais. Rio de Janeiro: IBGE.

Lakatos, E. M., Marconi, M. A. (2001). Metodologia do trabalho científico: procedimentos básicos, pesquisa bibliográfica, projeto e relatório, publicações e trabalhos científicos (5a ed.). São Paulo: Atlas.

Lima, G. S., Lima, M. S., \& Tanure, B. (2009). Os desafios da carreira da mulher executiva no Brasil. II Encontro de Gestão de Pessoas e Relações de Trabalho. Curitiba - PR.

Lodi, J. B. (1999). Fusões e aquisições: o cenário brasileiro. Rio de Janeiro: Campus.

Melo, H. P., Considera, C. M., \& Di Sabatto, A. (2007). Os afazeres domésticos contam. Economia e Sociedade, 16 (3), pp. 435-454.

Malhotra, N. K. (2005). Introdução à pesquisa de marketing. São Paulo: Prentice Hall.

Mourão, T. M. F., \& Galinkin, A. L. (2008). Equipes gerenciadas por mulheres: representações sociais sobre gerenciamento feminino. Revista Psicologia: Reflexão e Crítica (Vol. 21, n. 1, pp. 91-99).

Ouimet, G. (2003). Estratégias de poder e atores desprovidos de recursos. RAC (Vol. 43, n.1, pp. 1$11)$.

Rafferty, A. E., \& Griffin, M. A. (2004). Dimensions of transformational leadership: Conceptual and empirical extensions. The Leadership Quarterly (Vol. 15, n. 3, pp. 329-354).

Riche, L. (2009). A influência dos estilos de liderança nas empresas familiares. HSM Management (Vol.. 5, n. 67, pp. 67-122).

Robbins, S. P. (2002). Comportamento organizacional. São Paulo: Pierce Prentice Hall.

Souza, C. (2012). A neoempresa, a - o futuro da sua carreira e dos: negócios no mundo em reconfiguração. São Paulo: Integrare.

Revista de Gestão e Secretariado - GeSec, São Paulo, v. 4, n. 2, p 114-133, jul./dez. 2013. 

. (2007). Você é o líder da sua vida? São Paulo: Sextante.

Tannenbaum, R., \& Schmidt, W. (1986). Como escolher um padrão de liderança. In: Coleção Harvard de Administração (vol. 5). São Paulo: Abril.

Tanure, B. Carvalho Neto, A. M., \& Andrade, J. (2007). Executivos: sucesso e (in)felicidade. Rio de Janeiro: Campus Elsevier.

Weick, K. (1995). Sensemaking in Organizations. London: Sage Publications.

Weathersby, G. (1999). Leadership vs. management. In.: Management Review (Vol. 88, p. 5). 